\section{IMAGES (International Marine Past Global Changes Study)}

Nicolas Dittert ${ }^{1}$ and Ralph SchneideR ${ }^{2}$

${ }^{1}$ Research Center for Ocean Margins, University of Bremen, Germany; ndittert@uni-bremen.de Institude of Geosciences, University of Kiel, Germany; schneider@gpi.uni-kiel.de
IMAGES is an international collaborative science program aimed at the collection and interpretation of high-quality paleoclimate data from the global ocean. It aims to understand the role of marine processes in the Earth's climate system during the past million years at timescales relevant to human life and societal development. To further these aims, IMAGES organizes sea-going missions, thematic and regional working groups, workshops and conferences. IMAGES actively encourages, promotes and supports the participation of early-career scientists in its full range of activities, for example with ship-board opportunities ("University at Sea"), access to infrastructure, integration with research initiatives and participation at workshops.

Working groups form the heart of IMAGES. Organized around a scientific question or theme, a working group allows scientists from around the world to focus their questions and ideas, develop a plan, marshal the needed resources and work together towards success. Past working groups include those leading to coring expeditions, as well as many thematic working groups, such as millennial- to decadalscale climate variability, and last Glacial and Holocene climate conditions. These have provided new insights into the causes and consequences of past climate change in the ocean and on the continents.
Funding of IMAGES activities has been achieved through a combination of subscriptions/donations from member countries and the collective contributions of participating scientists in cruise campaigns. Currently participating countries include: Australia, Canada, Chile, China, Denmark, France, Germany, Iceland, India, Indonesia, Italy, Japan, Korea, Mexico, Netherlands, New Zealand, Norway, Portugal, Russia, South Africa, Spain, Sweden, Switzerland, Taiwan, Tunisia, UK, USA.

The ability of IMAGES to recover very long "giant" sediment cores is essential for meaningful time-coverage in the targeted high accumulation-rate sediment settings and well-described reconstructions of past climate change. In the mid-90's, IMAGES pioneered the use of a new Calypso Piston Corer; a device capable of routinely collecting undisturbed, continuous sediment sections up to $60 \mathrm{~m}$ in length and $12 \mathrm{~cm}$ diameter. Paired with other coring systems (e.g., the larger volume CASQ Corer) it provides scientists with a flexible, efficient method of obtaining sufficient amounts of sediment required to execute highest resolution, multi-proxy past climate reconstructions. Previously, such coring systems could be only be provided by the French R/V Marion Dufresne, however, IMAGES expects that more giant piston coring devices or alternative systems will be available on other vessels for future IMAGES needs (e.g., the Norwegian

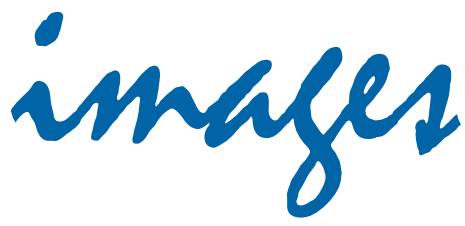

www.images-pages.org
R/V Sars, the US R/V Knorr, or the German MEBO portable submarine drill rig; PAGES News, 2006).

Up to now, in more than a dozen expeditions throughout the world oceans, IMAGES scientists have developed a remarkable archive of sediment cores that can be used for past climate change investigations. Recent cruises comprise the 2005 and 2006 Marco Polo 1 and 2 (MD 147, MD 155) and Pecten (MD 148) cruises, as well as the 2007 Pachiderme (MD 159) cruise. Reports can be requested from the IMAGES office. Coming up in 2008 are the Retro and Amocint cruises to the tropical and the northern Atlantic, respectively. Retro will investigate the response of tropical Atlantic surface and intermediate waters to changes in the Atlantic meridional overturning circulation, whereas Amocint will study the Atlantic meriodional overturning circulation during interglacials.

The scientific outcome of IMAGES cruises and thematic working groups comprises a large number of outstanding publications in high-level international journals, and has contributed to the IPCC reports by providing fundamental and detailed information about past climate changes with nearly global coverage. All IMAGES related information and data are archived at the World Data Centers for Marine Environmental Sciences (WDC-MARE, Bremen, Germany) and for Paleo-climatology (Boulder, USA).

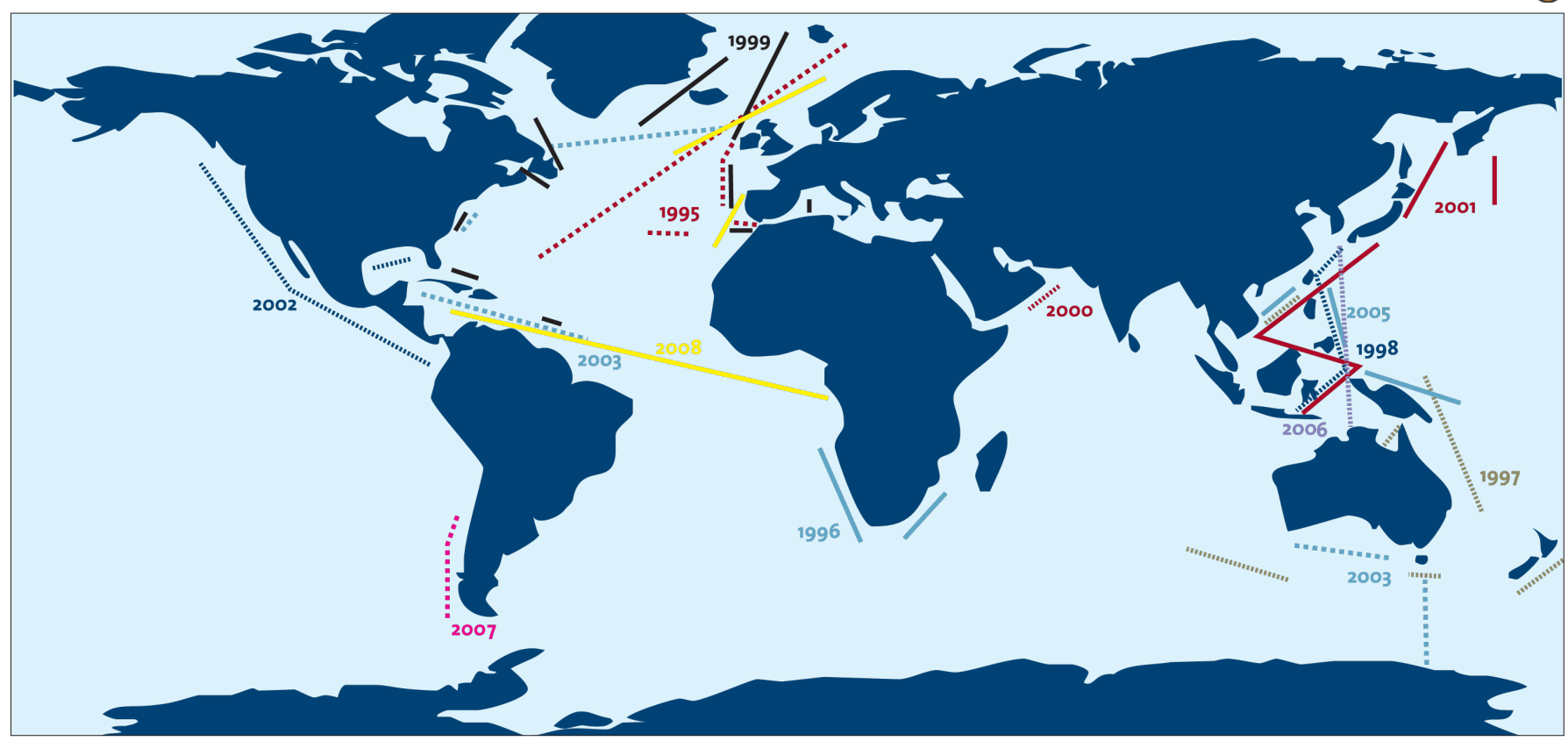

Figure 1: Overview of the regions where IMAGES cruises have taken place. Details of IMAGES cruises can be found at www.images-pages.org/cruises.htmI 